\title{
Assessment of groundwater quality in Jaisamand catchment for drinking purpose using geographical information system
}

\section{PRAVIN DAHIPHALE AND SANDIP NIKAM}

Received : 24.11.2016; Revised : 13.02.2017; Accepted : 27.02.2017

See end of the Paper for authors' affiliation

Correspondence to :

PRAVIN DAHIPHALE

College of Technology and

Engineering, Maharana Pratap

University of Agricultural

Technology, UDAIPUR

(RAJASTHAN) INDIA

Email : pravin.dahiphale59@ gmail.com
- ABSTRACT : The present study focuses on a GIS-based assessment and characterization of groundwater quality using pre monsoon and post monsoon groundwater quality data. Spatiotemporal variations of water quality parameters in the study area were analysed by using GIS techniques. Maximum area of Jaisamand catchment showed the drinking water quality within permissible limit. EC somewhat extent within permissible limit during pre monsoon period. Sulphate content also exceeded from permissible limit some extent in pre monsoon period but in post monsoon period it was within permissible range. The maximum total dissolved solids were found in western site of study area during pre monsoon period whereas in post monsoon period maximum area showed total dissolved solids within permissible range.

- KEY WORDS : Water quality, GIS, Assessment, Spatio-temporal

- HOW TO CITE THIS PAPER : Dahiphale, Pravin and Nikam, Sandip (2017). Assessment of groundwater quality in Jaisamand catchment for drinking purpose using geographical information system. Internat. J. Agric. Engg., 10(1) : 43-50, DOI: 10.15740/HAS/IJAE/10.1/43-50. 